

\title{
UMA NARRATIVA DA PAISAGEM
}

\author{
A LANDSCAPE NARRATIVE
}

\author{
Maria Angela Faggin Pereira Leite \\ Professora titular do Departamento de Projeto da FAUUSP \\ e-mail: mapleite@usp.br
}

\section{INTRODUÇÃO}

Para Umberto Eco "arquitetura é um ato de comunicação, uma mensagem, em que as partes ou a totalidade podem desempenhar o duplo papel de toda comunicação: conotar e denotar". Essa afirmação, extraída do texto Como uma exposição expõe a si mesma (ECO, 1987, p. 296, 299), encontra sua sustentação em outro texto seu denominado Função e signo: A semiótica da arquitetura (ECO, 1997), no qual afirma que a arquitetura constitui um desafio particular para a semiótica; em primeiro lugar porque, aparentemente, a maioria dos objetos arquitetônicos não comunica, mas funciona. Entretanto, uma consideração fenomenológica de nossa relação com os objetos arquitetônicos, contínua, mostra-nos que, normalmente, experimentamos a arquitetura como comunicação, mesmo quando reconhecemos sua funcionalidade (ECO, 1997, p. 182), isto é, o desenho de um objeto arquitetônico ou a imagem desse objeto a distância comunicam uma possível função, mesmo que não exista preenchimento dessa função e nem mesmo desejo de preenchê-la.

A dimensão comunicativa da arquitetura reside, portanto, no fato de, além de denotar uma função, os objetos arquitetônicos deverem conotar uma certa ideologia da função. E as capacidades simbólicas desses objetos não são menos úteis socialmente do que suas capacidades funcionais, isto é, embora possam não ser imediatamente identificadas com as capacidades funcionais em sentido estrito, as capacidades simbólicas representam, de fato, utilidades sociais dos objetos: graças ao complexo de convenções que uma função simbólica conota, ela permite certas relações sociais, ou as confirma, ou mostra sua aceitação por parte da sociedade, sua decisão de aceitar certas regras, etc.

Um objeto arquitetônico tem, então, ao lado de sua função utilitária - ou denotativa - algo de simbólico - ou conotativo - para comunicar e essas funções são objeto de sucessivas definições, determinadas por diferentes perspectivas ideológicas, novos contextos formais e novos códigos de leitura. "Portanto, no curso da história, ambas as funções - utilitária e simbólica - podem estar submetidas a perdas, recuperações e substituições de vários tipos... que podem ser vistas na variedade de leituras a que estão sujeitas as funções do objeto." (ECO, 1997, p. 190)

A maioria das discussões sobre a dimensão comunicativa da arquitetura, entretanto, ainda enfatiza o aspecto tipológico das configurações, o estilo dos objetos ou das 
intervenções, relegando a plano secundário o fato de uma ação arquitetônica dever contemplar as vicissitudes da comunicação e a variedade possível de interpretações e articulações externas à própria arquitetura. Em outras palavras, a prática da arquitetura exige sua inserção em um contexto, em determinada economia ou tecnologia ou sociologia e trabalha com a lógica desse contexto, mesmo que a intenção seja a de, por meio de uma intervenção formal, negar essa lógica.

A prática da arquitetura obriga, então, a projetar objetos que, inseridos em um sistema sobre o qual a arquitetura não tem poder de comando, abram possibilidades de gerar significados explícitos daquilo que ali está presente de forma implícita.

Nossa informação sobre o mundo sempre foi mediada. Mas, enquanto no passado essa mediação era "unitária", na atualidade a informação, a ciência, o desenvolvimento tecnológico, produzem uma mediação "contraditória" em que proliferam inúmeras perspectivas políticas e sociais que dificultam a identificação das imagens com a realidade, a mesma sobre a qual sabemos tudo instantaneamente, mas quase nada diretamente.

A arquitetura se obriga, assim, a pensar em termos de totalidade mesmo quando atua sobre o específico, porque as sucessivas conotações que os objetos arquitetônicos adquirem historicamente, indicam, em última instância, que, para produzir uma imagem de mundo, é preciso considerar muitas imagens diferentes. Isso não pressupõe a existência de uma imagem única da realidade, mas apenas indica a impossibilidade de vincular a dimensão comunicativa da arquitetura exclusivamente à interpretação funcional de seus objetos. E, de modo análogo, põe em discussão a legitimidade do projeto apoiado em ideais clássicos, naturais ou históricos. Qual é a medida ideal das edificações ou do planejamento de cidades? Quais são as necessidades naturais da sociedade e como distingui-las daquelas produzidas pelo mercado, das supérfluas, das não-naturais? Nessas condições, nesse mundo de modelos múltiplos, não estaria a legitimidade do projeto apoiada na multiplicidade, na afinidade simbólica, na dimensão conotativa de os objetos e a arquitetura se revestirem quando contextualizados?

A arquitetura como ato de comunicação pressupõe, desse modo, planos e projetos enraizados no lugar, mas, ao mesmo tempo, com uma carga conotativa tal, que permita à sociedade vê-los como estruturas passíveis de gerar significados múltiplos e preenchê-los com seus próprios significados latentes. De modo análogo, o paisagismo visto em sua dimensão comunicativa expressa as sucessivas formas de relação entre a sociedade, a natureza e a paisagem, revelando, por meio das conotações que assume no tempo, as múltiplas facetas dessa relação.

As matrizes culturais do paisagismo coincidem com mudanças no modo de considerar a natureza, decorrentes do interesse estético que as paisagens naturais passaram a despertar nas sociedades urbanas afetadas pela Revolução Industrial no século 18. Essas mudanças não se exprimiram apenas esteticamente, por uma atitude "diferente" em relação à natureza, mas também conceitualmente, na mimese atenta e rebuscada da inesgotável variedade de formas, cores e sensações presentes na paisagem natural.

Apesar de sua aparente negação do urbano, o paisagismo caracterizava, tal como a ancestral atividade de criar jardins, uma atividade de projeto baseada em princípios 
compositivos, estéticos, formais e no conhecimento dos materiais, dos elementos naturais - solos, rochas, água, árvores, arbustos, luz e sombra - e de suas principais características. Sua função, descrita em 1917 por Hubbard e Kimball no livro An introduction to the study of landscape design, consistia em "criar e preservar a beleza da ampla paisagem campestre e dos territórios que circundam as habitações humanas, melhorando o bem-estar, a comodidade e a saúde da população urbana".

A despeito de suas aproximações naturalísticas, o paisagismo, tal como a arquitetura, trai, desde o início, a intenção de informar o real, de organizá-lo, depurá-lo, humanizá-lo, visando à construção perfeita de um ideal universal de paisagem: refletir sobre a paisagem e intervir sobre ela supõe organizar seus elementos com a mediação de uma ideologia que marca, no tempo, os valores culturais da sociedade.

O conhecimento dos materiais - aí incluídos os elementos naturais e suas propriedades - é condição para projetar associações entre formas, cores e volumes, cujo resultado será um objeto que, ao lado de sua função utilitária, possa estabelecer com o existente um diálogo contextual simbólico, capaz de criar lugares informados. Não é difícil, então, reconhecer, no paisagismo, funções denotativas e conotativas as quais, mais do que qualquer outra semelhança técnica ou projetual, aproximam-no da arquitetura como ato de comunicação.

As sucessivas conotações que se pode atribuir à paisagem, ao longo da história são, a uma só vez, possibilidades de representação do movimento total da sociedade e das expressões locais desse movimento. A sintonia entre o paisagismo e esses movimentos revela suas características de ato de comunicação, por meio das definições, perspectivas ideológicas e códigos de leitura que ele assume em diferentes contextos.

movimento do paisagismo em sua relação com a arquitetura e com os diversos ideais de paisagem é o tema deste texto que tem, também, a intenção de apontar as contradições e, especialmente, as dificuldades as quais as atividades acadêmicas encontram para exprimir, em seu âmbito, aquilo que a sociedade constrói em seu movimento contínuo, movimento que inspira, ou deveria inspirar, a atuação da Universidade.

\section{PAISAGISMO}

A natureza é histórica. $\bigcirc$ expediente metodológico de separá-la da cultura ou de defini-la como aquilo que não foi tocado pelo homem termina sempre por trazer à discussão o fato de a natureza não se nomear como tal, não demarcar a si mesma e sua utilização, organização, conservação, preservação ou extinção resultarem da história da sociedade que sobre ela atua pelo trabalho.

Construir - e por vezes defender - os lugares de vida de uma sociedade, elaborando uma reflexão estética da e sobre a paisagem, atribuindo valor às suas diversas feições, parece ser, ainda hoje, a preocupação a definir o escopo do paisagismo, que acompanha, nesse sentido, a evolução do urbanismo em sua constante procura do ideal de cidade, em que pesem as inúmeras conotações que ele se atribui ou que a ele são atribuídas. 
O ensino de paisagismo iniciou-se, no Brasil, na Escola Nacional de Belas Artes, no Rio de Janeiro, com as atividades de formação dos pintores paisagistas, nas primeiras décadas do século 20.

Em São Paulo, iniciou-se com a fundação da Faculdade de Arquitetura e Urbanismo da USP, em 1948, marcado pelas mesmas questões que levavam a arquitetura a discutir os problemas de uma sociedade a qual se industrializava e urbanizava aceleradamente.

Desde a década de 1920, as esperanças de transformação social do mundo impregnavam a arquitetura moderna da necessidade de discutir e propor as mudanças necessárias para que as cidades correspondessem àquelas expectativas. "A exaltação social da arquitetura (moderna) em seu nascimento, na década de 20... foi de tal ordem que a casa popular passou a ser o maior monumento do século XX... Mas a verdade é que um dos fatores que surgiu imediatamente a partir da consideração da casa foi o alargar desses conceitos para o habitat humano. $O$ arquiteto passou, então, a pensar como deveria ser a cidade, o conjunto das casas ligadas entre si - e começou a formular as modificações necessárias." (ARTIGAS, 1989, p. 14, 15)

Essas idéias a respeito da cidade ou, mais exatamente, a respeito da relação entre os espaços edificados e não-edificados na cidade, tiveram influência decisiva, também, na formulação das teorias paisagísticas. Nos anos 40, as intensas mudanças sociais do pós-guerra forneceram condições para o surgimento e a consolidação, na Califórnia, do paisagismo moderno. A valorização da natureza e do espaço externo, marca das propostas de intervenção paisagística daquele período, chegaram ao Brasil pelas mãos de Roberto Coelho Cardozo, responsável pela disciplina de Paisagismo integrante do currículo da FAU em sua fundação. De origem fundamentalmente urbana, aquelas propostas destacavam, também, as questões sociais e econômicas emergentes do adensamento das cidades e da generalização do uso do automóvel, com mudanças importantes na relação entre espaços livres e edificados, cujos modelos, no caso brasileiro, vinham de fora do país.

Jardins, parques e espaços públicos deveriam promover o encontro de pessoas e o papel da vegetação deveria ser o de contribuir, como um dos elementos do projeto de paisagismo, para a estruturação de espaços livres com essa finalidade. Essa visão social do espaço público não foi, entretanto, capaz de alterar o quadro urbano que se formava, com "estruturas de organização física e de serviços deficientes ou inexistentes e total descaso pelos espaços coletivos da população" (MAGNOLI, 1981, p. 61, 62).

A partir dos anos 30, Roberto Burle Marx começou seu trabalho como paisagista no Brasil, elaborando projetos de praças e parques urbanos no Recife. Longe, ainda, dos problemas resultantes do adensamento das cidades ou do uso generalizado do automóvel, propunha-se a utilizar, em seus projetos, plantas da caatinga ou da floresta amazônica, para responder aos apelos modernizantes dos arquitetos e urbanistas do Brasil que, segundo Lucio Costa, "... foram justamente aqueles poucos que lutaram pela abertura para o mundo moderno e que mergulharam no país à procura das suas raízes, da sua tradição..." (COSTA,1995, p. 116). 
Sua preocupação com a organização e a estrutura das praças, parques e jardins - evidenciando sua dimensão construtiva - associada à intenção de contribuir para a formação de uma cultura brasileira de uso desses espaços - intenção sempre reiterada em suas inúmeras entrevistas - apropriou-se das tradições urbanísticas do país para construir uma obra paisagística que fez o jardim entrar na modernidade. Uma obra na qual se mesclavam geometria, cor, conhecimentos botânicos e uma cuidadosa atenção para com os usuários dos projetos propostos. "Essa atenção para com o público iria, igualmente, aproximá-lo dos arquitetos e urbanistas, tendo em vista que seu desejo não era apenas o de compor belos jardins para particulares, mas de trabalhar para todos e, por conseguinte, trabalhar dentro da cidade e para seus parques públicos." (LEENHARDT, 1996, p. 15)

Segundo o próprio Burle Marx, a missão social do paisagista compreende, sem sombra de dúvida, um aspecto pedagógico: cumpre-lhe fazer entender e amar o que a natureza representa, comunicar às multidões o sentimento de apreço e compreensão de seus valores pelo contato com jardins e parques (BURLE MARX, 1996, p. 50). Para que esse contato fosse eficiente, a observação acurada do entorno deveria sugerir formas de sistematizar, em seus parques e jardins, relações entre sociedade e natureza que pressupunham um projeto urbano como fundamento. E qual projeto urbano era esse, senão o mesmo defendido pela arquitetura moderna? Tratava-se, igualmente, de contar com o paisagismo, tal como com a arquitetura, "como instrumento capaz de fazer as mudanças necessárias para o país inteiro" (ARTIGAS, 1989, p. 14).

Parecia, assim, natural que o ensino de paisagismo estivesse integrado ao currículo dos cursos de arquitetura e urbanismo, dada a convergência de suas proposições na direção de moldar cidades onde as necessidades de contato, comunicação, organização e troca fossem preenchidas por meio dessas intervenções com preocupações explicitamente sociais e comunitárias.

Para Lucio Costa (COSTA, 1995, p. 271), constituiu-se "num dos preceitos da urbanização moderna o contraste entre a rigidez, a simetria, a disciplina da arquitetura e a imprecisão, a assimetria, o imprevisto da vegetação". Essa provável referência às tentativas da arquitetura moderna brasileira de superar a oposição cidade/natureza, por meio de uma comunhão simbólica entre arquitetura e paisagismo, comunicava o ideal de perseguir e delimitar o sonho da cidade perfeitamente integrada à natureza que a circundava. Essa espécie de modelo de urbanização, ao mesmo tempo em que tratava de justificar, como necessidades de organização das cidades contemporâneas, o rigor e a disciplina, reclamava implantações vegetais capazes de atenuar os excessos dessas aglomerações e de emoldurar, destacando, algumas de suas formas arquitetônicas.

Os mais marcantes aspectos metodológicos da obra de Burle Marx - seleção de conjuntos de plantas adequadas ao lugar e ao clima, em associações baseadas nas próprias associações naturais, dispostas de forma a valorizarem-se mutuamente por seu próprio inter-relacionamento - evidenciavam-se nos projetos realizados para áreas de uso público, reiterando sua visão do parque urbano como forma de assegurar o 
conhecimento da flora brasileira às populações urbanas. Não ignorava outras funções dos parques, como lazer ou convívio e, tampouco, as funções de climatização que a vegetação pudesse assumir nessas áreas. Mas sua proposição didática parecia prevalecer sempre sobre as outras - mesmo as urbanísticas - em raciocínio, talvez ingênuo, de o conhecimento generalizado da flora poder inverter a tendência de dilapidação do patrimônio vegetal brasileiro e, em etapa posterior, esse conhecimento adquirido contribuísse para modificar a relação cidade/natureza.

Essas preocupações, em seus desdobramentos, destacaram o uso da vegetação nas áreas urbanas com uma compreensão distorcida, que investia a massa vegetal de poderes e responsabilidades muito além de suas reais possibilidades. $\bigcirc$ "verde", imediatamente identificado como paisagismo e encarregado de controlar fenômenos microclimáticos ou de acabar com a polvição atmosférica, criou mitos que em nada beneficiaram as cidades, porque se apoiavam em tentativas de implantação que não se faziam acompanhar de estudos globais, não levavam em conta as questões escalares das intervenções e não traziam modificações substanciais nas relações entre a cidade e a natureza.

Por outro lado, as teorias defendidas por McHarg em 1968 pareciam iluminar zonas obscuras dessa relação, alargando o campo do paisagismo pela incorporação, ao conhecimento sobre a vegetação, de conhecimentos relativos ao "sistema natural". O movimento ecológico, pano de fundo para o desenvolvimento dessas teorias, criticava o modelo de desenvolvimento econômico mundial que se delineava para a década de 1970, por sua incapacidade de solucionar os conflitos sociais e de controlar a utilização dos recursos naturais, utilização que, na visão dos ecologistas, exigia uma criteriosa revisão.

Sob a influência de idéias - discutíveis - geradas pelos polêmicos debates conduzidos pelo Clube de Roma, em abril de 1968, McHarg publicou, um ano mais tarde, o livro Design with nature, cuja tônica estava na necessidade de compatibilizar, nas propostas de intervenção paisagística, processos naturais e sociais. Seu conteúdo, porém, foi imediatamente interpretado como um método de projeto paisagístico que privilegiava os aspectos naturais da paisagem, sem que se tivesse dedicado maior atenção aos argumentos ali contidos em defesa das intervenções locais como resultado do entendimento integrado, em escala regional, de processos de organização natural, social, econômica e histórica.

A apropriação parcial, pelo paisagismo, das idéias de McHarg, colocava em plano secundário as complexas relações existentes entre parâmetros sociais e paisagem construída, apoiando-se mais em considerações visuais do que de desenvolvimento econômico e deixando de lado os problemas de atraso, pobreza e superpopulação que originaram as discussões do caráter ecológico da paisagem, propostas pelo autor. Mais que isso, voltou-se ao embate entre a cidade e a natureza, com o paisagismo identificando-se como negação ou forma de resistência à urbanização.

As intervenções paisagísticas, agora com caráter e conotações mais fortemente naturalísticas, revelavam preocupações com preservação e conservação da natureza, 
incorporando, aos conhecimentos botânicos, um discurso ecológico elaborado como condenação explícita às práticas da arquitetura moderna.

Por outro lado, a arquitetura ensaiava a adoção de estudos ambientais como estratégia de mudanças sociais e procurava sua integração com problemas emergentes da sociedade. A projeção do fato biológico sobre a dimensão social e econômica da paisagem era uma tentativa de encontrar um denominador comum para as questões naturais e urbanas e de contornar os exageros que o determinismo do conceito de ecossistema tentava impor aos estudos paisagísticos.

A eclosão da questão ambiental, da qual são marcos importantes as reuniões de Paris em 1968 e de Estocolmo em 1972, implicou em uma série de discussões sobre o pensamento econômico, especialmente quanto ao "livre arbítrio" das decisões de desenvolvimento inteiramente despreocupadas com a natureza, vista, até então, como mera fornecedora de recursos. Porém, não se tratava mais de cotejar a competência da sociedade em alterar a natureza e a capacidade da mesma de resistir aos impactos da produção e do consumo: era preciso desnudar o preconceito mítico do equilíbrio ecológico, sempre pronto a avaliar a capacidade de regeneração dos sistemas naturais, opondo-os ao capitalismo e sua atuação; era preciso enfrentar a fragmentação do objeto de estudo da arquitetura - a cidade - em inúmeras dimensões aparentemente opostas e isso exigia disposição para a pesquisa e o ensino específico de questões da paisagem nos cursos de arquitetura.

\section{SISTEMAS}

Sem retomar discussões já esvaziadas de sentido, é necessário reconhecer que o fio condutor das ciências naturais, que até a década de 1960 exerceram influência decisiva sobre o paisagismo brasileiro, é a crença de o conhecimento científico ser uma representação de algo exterior a nós. É essa crença que explica e justifica a sistematização compulsiva da natureza, a classificação que pretende fornecer uma explicação do mundo por sua segmentação e hierarquização. Após a formulação de T. Kuhn, em A estrutura das revoluções científicas, o máximo a que os estudos naturais se permitiram foi aceitar que classificações são possibilidades de visão do mundo, influenciadas por questões morais, éticas e filosóficas.

É inegável que essa tendência de ilustrar a organização da natureza por meio de sistemas os quais representassem ou reproduzissem suas associações elementares, impregnou durante muito tempo a prática do paisagismo. Não era essa a intenção de Burle Marx ao construir, para uso e fruição do público, parques e jardins, em suas próprias palavras, didáticos e enciclopédicos? E não era essa ilustração do convívio harmônico entre a obra humana e a ordem natural que transparecia nos jardins, elaborados como molduras de natureza, destacando os edifícios da arquitetura moderna?

Durante a década de 1960, porém, as ciências que se ocupavam das relações espaciais começaram a incorporar a teoria de sistemas ao seu corpo de conhecimen- 
tos, para elaborar análises quantitativas que pretendiam constituir-se em alternativas a seus métodos correntes de interpretação e análise. As cidades e, especialmente, as redes urbanas, foram objeto constante dessa experimentação metodológica que se alimentava do polêmico artigo publicado por Brian Berry em 1964, com o significativo título de "Cities as sistems within sistems of cities". Nesse texto o autor declarava que as cidades poderiam ser consideradas como sistemas passíveis de serem estudados e analisados como qualquer outro sistema e caracterizados pelas mesmas generalizações, construções e modelos.

Entretanto, essa aplicação da teoria de sistemas aos estudos urbanos contemplava apenas o momento presente, eliminando todo o processo pretérito de construção das relações sociais e ambientais que, posto em dimensão temporal, sustenta o desenvolvimento dos estudos de urbanização.

A paisagem não escapou a essa imposição metodológica. Considerada como sistema, era também suscetível da correspondente análise quantitativa, que buscava, na hierarquia, uma explicação para localizações ou polarizações.

Por outro lado podia, também, ser entendida como um conjunto composto por elementos estruturados segundo relações recíprocas, sociais e materiais, passível de organização não por meio de um modelo ou de uma hierarquização, mas pela interpretação e representação. E nossas interpretações e representações do mundo são construídas socialmente, isto é, resultam da intenção de conhecer o objeto por ações que terminam por alterá-lo.

Para Umberto Eco, o mundo é um continuum e não uma série de estados discretos e, portanto, é segmentável, mas não segmentado. "Então, é a mente que - por limitação própria - não pode pensar o continuum senão segmentando-o em stoicheia, para torná-lo análogo à natureza discreta de seu sistema de símbolos. Digamos, então, que os stoicheia, mais do que estados reais do mundo, são possibilidades, tendências de representá-lo através de seqüências discretas de símbolos", um modelo rígido que está sempre posto à prova por nossa impossibilidade de descrevê-lo em sua integridade (ECO, 1997, p. 25).

Ao admitir que a paisagem pode ser vista como um continuum - segmentável, mas não segmentado - e submetida, permanentemente, à reorganização decorrente da atuação da sociedade sobre ela, o paisagismo se obrigou a enfrentá-la, a paisagem, com a perspectiva social da intervenção e não mais com a perspectiva naturalística da observação/reprodução, e a admitir que a intervenção é capaz de desencadear um processo evolutivo distinto daquele produzido pela evolução natural. Perdeu-se não só o sentido de reproduzir organizações vegetais elementares - os conjuntos de plantas em associações naturais - com a intenção de demonstrar a possibilidade de convívio harmônico entre o natural e o construído - como também o de observar e interpretar o objeto - a paisagem e não apenas sua dimensão natural - de um ponto de vista exterior a ele.

Assim considerada, a paisagem constituía um sistema, um conjunto composto por elementos estruturados segundo relações recíprocas, temporais e espaciais. Isso exigia 
a consideração simultânea de sua estrutura e de seu processo, da dinâmica de sua organização e da relação entre seus elementos estruturantes. Vê-la como sistema com essas características constituía um desafio constante à nossa capacidade de formular, a seu respeito, juízos estéticos severos e uniformes, visto que possuía um potencial ilimitado de alterar as regras do jogo, em decorrência de sua própria dinâmica.

Por outro lado, a configuração da paisagem das cidades brasileiras, especialmente da cidade de São Paulo, espelhava já a desigualdade social e as pressões de produção e consumo, de modernização e utilização de recursos, questões de essência política, que deixavam entrever uma participação incipiente da sociedade brasileira na construção de seu território.

Em termos de ensino, o novo, dentro desse enquadramento da questão, decorria muito mais do entendimento da paisagem como uma instância espacial dependente da história política, econômica e cultural da sociedade, do que das tentativas de entender sua organização sistêmica por sua divisão em unidades elementares ou diferenciadas, que privilegiavam aspectos fisiográficos em detrimento do significado social.

A década de 1980, no Brasil, seria particularmente reveladora, em termos de configuração da paisagem, do conflito instalado entre o desenvolvimento econômico e a proteção ao ambiente e à qualidade de vida das populações.

O processo brasileiro de desenvolvimento, pelo próprio modelo que adotou, sempre foi um importante patrocinador de impactos sobre o ambiente. A leitura dos planos nacionais de desenvolvimento, elaborados pelo governo federal na década de 1970, deixa entrever como viriam a ser intensas e extensas as pressões desenvolvimentistas sobre as estruturas sociais e produtivas do país.

Declarando, em 1974, por ocasião da apresentação do II PND, sua intenção de realizar o desenvolvimento sem deterioração da qualidade de vida e, em particular, sem devastação do patrimônio de recursos naturais do país, o governo procedeu, "imediatamente, a toda pressa e a qualquer custo, à abertura e valorização dos 'espaços vazios' do território, cuja aparente improdutividade corria o risco de ser interpretada como inoperância oficial" (MONTEIRO, 1981, p. 24). Mas, ao mesmo tempo, as áreas que envolviam os locais dos grandes investimentos programados pelo governo não eram nem mesmo mencionadas e seu desenvolvimento não estava previsto, nem ao menos como forma de sustentação a esses empreendimentos.

A teoria de sistemas aplicada aos estudos urbanos, por sua vez, deixara como herança a visão da rede urbana como uma estrutura auto-suficiente em relação às demais funções do território, permitindo todo tipo de abstração em termos de planejamento.

O que se armava, no que diz respeito à configuração territorial, era o desligamento completo entre o lugar e a intervenção. A visão integrada entre a cidade e sua região de influência não ocorria na esfera governamental, na qual os planos de desenvolvimento tinham vínculos mais fortes com aspectos macroeconômicos do que com aspectos sociais. Tampouco na esfera da sociedade civil, na qual as reivindicações, quando formuladas, eram sempre pontuais e guiadas pela comunhão momentânea dos interesses de certos grupos sociais. 
Os estudos da paisagem em escala regional pareciam capazes de contribuir para destrinchar, no plano teórico, os exageros que a aplicação indiscriminada da teoria de sistemas aos estudos urbanísticos havia produzido e essa possibilidade era muito tentadora.

\section{ESPAÇO}

Existe uma crença difusa de o paisagismo ser uma ciência de síntese, uma crença que uma abordagem paisagística da cidade e de seu entorno, mesmo balizada por premissas enraizadas em aspectos conjunturais, permite a interpretação global do fenômeno urbano no tempo e no espaço. Essa crença, que confunde a ciência - o paisagismo - com seu objeto - a paisagem - e contribui, enormemente, para deformar a realidade que se deseja interpretar, tem origens profundas e antigas a mesclarem-se com a tradição de elaborar o conhecimento com base em dados circunstanciais condicionando, não só a prática profissional, mas também o ensino e a pesquisa, à discussão dos conceitos e não das coisas.

A visão do paisagismo brasileiro como possibilidade de harmonizar a obra humana e a condição natural, por exemplo, constituía uma formulação localizada da atuação profissional nas décadas de 1940 e 1950 deste século, condicionada por circunstâncias políticas e econômicas que jamais se difundiram por todo o território, mas influenciaram, decisivamente, a proposição de programas de ensino e de pesquisa em escala nacional.

Do mesmo modo, a visão da paisagem como um sistema - ou do paisagismo como um tipo especial de teoria de sistemas - muito difundida nas décadas de 1960 e 1970, refletia as circunstâncias particulares da estrutura das metrópoles brasileiras, cuja complexidade induzia o pensamento a hierarquizar o objeto - a paisagem - em classes contidas dentro de classes, privilegiando a materialidade dos elementos em detrimento das ações que eles sugeriam ou a que estavam submetidos. Se, no primeiro caso, como já foi aqui referido, o obstáculo a ser superado era a tendência de observar e interpretar a paisagem com base em referencial exterior a ela, no segundo caso o problema estava na visão da paisagem como sistema de objetos fixos e desvinculados de seu uso, forma cujo valor analítico é discutível, na medida em que confunde as coisas com o valor que lhes é atribuído. A superação dessa questão, como se verá, passou por uma reviravolta teórica iniciada com a preocupação dos paisagistas pesquisadores em construir um sistema interpretativo que permitisse compreender o processo de produção da paisagem. A parceria do paisagismo nessa busca foi, mais uma vez, a geografia.

As articulações específicas entre as diversas variáveis que configuram o espaço, presença importante nos estudos de geografia, encontraram correspondência na procura de interação entre as formas visíveis e a trama parcialmente invisível da estrutura social a qual, instável e dinâmica, redefine constantemente os valores da paisagem, condicionando a atuação do paisagismo. A síntese de todas essas variáveis, para Milton Santos, é dada pelo espaço, construção social, conjunto indissociável do sistema de ações e do sistema de objetos. Estávamos, assim, arquitetura e geografia, unidos pelo espaço 
e a questão a ser posta então, era, ainda nas palavras de Milton Santos, a da "própria natureza do espaço, formado, de um lado, pelo resultado material acumulado das ações humanas através do tempo e, de outro lado, animado pelas ações atuais que the atribuem dinamismo e funcionalidade. Paisagem e sociedade são variáveis complementares cuja síntese, sempre por refazer, é dada pelo espaço humano" (SANTOS, 1996, p. 85, 86).

Um sistema espacial - e a paisagem vista sob essa ótica - é o resultado de um jogo de relações que só pode ser completamente entendido se considerarmos que esse sistema se define por um centro, uma periferia e um fluxo de difusão, que projeta sobre a periferia as inovações originadas no centro. Essas inovações são responsáveis tanto pela criação de objetos quanto por novas formas de utilização dos objetos existentes. Voltamos, aqui, à questão da denotação e da conotação.

entendimento da paisagem como um produto, um conjunto de objetos, seria, então, uma abstração, na medida em que, esvaziados de suas capacidades simbólicas, esses objetos denotariam sempre as mesmas capacidades funcionais, estáveis e cativas de um código absoluto e imutável. Os elementos do conjunto denotariam, eternamente, as mesmas funções, estabelecendo uma espécie de proposição necessária e definitiva da paisagem, interrompendo o fluxo difusor das inovações. Mas a funcionalidade dos objetos que constituem um sistema espacial é sempre socialmente experimentada e, portanto, submetida a ações as quais, ao longo do tempo, qualificam esses objetos, permitindo-lhes assumir conotações sucessivas. São as conotações que, ao mesmo tempo em que relativizam as funções dos objetos, revelam a ideologia da construção do sistema. Criam-se objetos, formas de utilização dos objetos existentes e é assim que o espaço se transforma. "Os objetos não têm realidade filosófica, isto é, não nos permitem o conhecimento se os vemos separados dos sistemas de ações. Os sistemas de ações também não se dão sem os sistemas de objetos... O espaço é formado por um conjunto indissociável, solidário e também contraditório de sistemas de objetos e sistemas de ações, não considerados isoladamente, mas como quadro único no qual a história se dá." (SANTOS, 1996, p. 51).

A paisagem, portanto, não constitui um sistema autônomo, mas inscrita no espaço, conjunto indissociável de sistemas de objetos e sistemas de ações, constitui uma representação localizada da articulação entre certos objetos e certas ações, um fragmento da realidade total que temos diante de nós, um a priori do qual partimos para conhecer a realidade total.

A paisagem é uma integridade momentânea e visualmente sensível, que nos permite abordar a realidade a partir de um ponto de vista interior a ela. Objeto do paisagismo, a paisagem informa sobre a articulação entre os aspectos tangíveis, ou não, da realidade social. $\bigcirc$ paisagismo atua sobre essa realidade pela produção de objetos e sofre a atuação da realidade por meio da paisagem em que esses objetos se inserem. $\bigcirc$ que é passível de generalização e síntese, portanto, são as regras de funcionamento da realidade total e não suas articulações localizadas - os lugares - os quais apenas nos fornecem pontos de apoio para a construção de sistemas analíticos e interpretativos, cuja finalidade última é o conhecimento da sociedade. "A sociedade, que deve ser, 
finalmente, a preocupação fundamental de todo e qualquer ramo do saber humano, é uma sociedade total. Cada ciência particular se ocupa de um de seus aspectos. O fato da sociedade ser global, consagra o princípio da unidade da ciência. O fato dessa realidade total, que é a sociedade, não se apresentar a cada um de nós, em cada momento e em cada lugar, senão sob um ou alguns dos seus aspectos, justifica a existência de disciplinas particulares. Isso não desdiz o princípio da unidade da ciência, apenas entroniza outro princípio fundamental, que é o da divisão do trabalho científico." (SANTOS, 1980, p. 115)

O paisagismo deve, então, voltar-se para o estudo do singular, não como princípio de generalização, mas como forma de acesso ao conhecimento da sociedade, como busca de um sentido para as ações humanas. E sua tendência em enfatizar o empírico como explicação privilegiada desse sentido encontra um obstáculo inesperado: o empírico leva a generalidades empobrecedoras; apenas os sistemas interpretativos podem dar conta das particularidades.

$\mathrm{Se}$, por um lado, o singular nos interessa, aos paisagistas, como campo de atuação, são os sistemas interpretativos os quais nos permitem compreender o processo de produção da paisagem e as peculiaridades das relações sociais que, simultaneamente, influenciam e são influenciadas por nossas intervenções concretas.

A paisagem não pode ser entendida com base nos objetos que a compõem, como se tais objetos tivessem vida própria ou pudessem explicar-se por si mesmos. Os objetos são importantes porque sua materialidade sobrevive aos modos de produção que Ihes deram origem - ou aos diferentes momentos desses modos de produção - mas não são vetores de mudança. Objetos são construções perfeitas e, por isso, duros e insensíveis. Sua racionalidade técnica nos desencoraja a vislumbrar, a partir deles, possibilidades de transformação social, embora tenham, hoje mais do que antes, um papel importante porque, partindo de uma certa produção de objetos e de uma certa disposição de objetos, podemos ajudar, ou não, na produção de um sentido para as ações da sociedade.

E é a paisagem, com suas desigualdades, heterogeneidades, diversidades e complementaridades, o veículo privilegiado para compreender essas ações ou reafirmar os valores sociais. A paisagem é o espaço - conjunto indissociável entre o sistema de objetos e o sistema de ações - visto em perspectiva.

\section{INTERTEXTO}

Normalmente, não pensamos na paisagem como uma narrativa. Para Potteiger e Purinton (POTTEIGER; PURINTON, 1998, p. 3, 5), uma narrativa, que pode ser tão simples como uma sentença ou tão extensa e complexa como a noção de progresso, é um modo de pensar fundamentalmente diferente do modo de conhecimento lógico-científico, porque exige atenção às conexões particulares, coincidências e casualidades e seu significado não reside exatamente naquilo que é narrado, mas em como é narrado.

A narrativa é um processo de transformar conteúdos em expressões; utiliza-se de eventos ou de sua seqüência; por exemplo, para estruturá-los em manifestação verbal, ou 
visual, ou espacial; trabalha com o repertório cultural, individual ou coletivo, para sugerir escolhas ou produzir significados a partir de fatos sociais aparentemente desconexos.

Sob essa perspectiva, a paisagem não apenas abriga muitas histórias, como é, ela mesma, um processo e uma representação, mutável e acidentada, que engendra muitas histórias. A paisagem, naturalmente, não nos conta seu passado, mas o contém, na medida em que combina duas dimensões: uma seqüência temporal de eventos e uma configuração não-sincrônica, organização espacial dos eventos em narrativas. Uma narrativa, mais do que uma história, mostra-nos processos naturais e culturais que, organizados pelo observador, revelam o sentido histórico das ações humanas.

De outro lado, o projeto, a intervenção paisagística, é também uma seqüência organizada de etapas e contém uma história, explícita ou implícita. Nada pode ilustrar melhor esse argumento do que alguns jardins renascentistas, entre eles os da Villa Lante, em Bagnaia, Itália, ilustração espacial das metamorfoses de Ovídio, narrativa desenhada na paisagem por meio de esculturas, topografia, vegetação e fontes, alegoria a possibilitar ao visitante interpretações da mitologia e da história.

Não sendo exclusivo dos jardins renascentistas, esse tipo de narrativa esteve presente, também, nos jardins antigos da Índia, da China e do Japão, onde a utilização de elementos com forte simbolismo cultural procurava tornar visível o mundo invisível da espiritualidade e do significado da vida. Mas também em inúmeros projetos recentes, como os jardins enciclopédicos de Burle Marx, já comentados neste texto, ou no projeto de Henry Cowle para as Dunas de Indiana, às margens do lago Michigan, EUA, narrativa de uma sucessão ecológica construída com base nas formas e processos naturais que, ao longo do tempo, moldaram aquele lugar único, preservado como um parque. Ou no projeto de Geoffrey Jellicoe para os Moody Gardens, no Texas, EUA, um tipo especial de jardim botânico que narra a relação do homem com a paisagem ao longo da história. Ou nos inúmeros jardins botânicos do mundo, onde o percurso nos indica um tipo particular de narrativa: a do entendimento humano do que seja a organização e a evolução do mundo natural.

Como em qualquer projeto, as narrativas espaciais empregam estratégias para delimitar ou circunscrever um significado com capacidade potencial de abrir-se para associações, referências ou códigos que estão além das intenções de seu autor. As dificuldades em controlar um significado no interior de uma narrativa originam-se não apenas de associações inesperadas, ou da falta de precisão da linguagem empregada, senão da própria natureza da linguagem, que produz significados relacionais decorrentes de diferenças e comparações, resultando em uma espécie de constante deslizamento do significado inicial. Mas paisagismo como narrativa deve enfrentar, além da questão da linguagem e de sua natureza, a da autoria múltipla, aumentando, ainda mais, a pluralidade e a complexidade de seus significados.

A propósito, por exemplo, dos jardins da Villa Lante, Potteiger e Purinton (op. cit., p. 56), indagam quem seria seu autor: o arquiteto, os sucessivos proprietários que fizeram modificações no projeto original, ou a família Lante della Rovere, que os manteve por quase três séculos, com seu nome profundamente vinculado ao lugar? Ovídio 
teria algum crédito? E qual tipo de crédito deve-se atribuir a quem concebeu o sistema das fontes que interliga os terraços? Ou aos visitantes os quais, ao longo do tempo, adicionaram outros significados e referências ao projeto?

Existe, certamente, dentro do projeto em si, uma rede ilimitada de significados latentes, de lacunas, silêncios ou disposições específicas, capazes de alterar sua unidade original, resultando em interpenetração de significados, um intertexto, terminando por requalificar não apenas o projeto, mas toda a paisagem que o acolhe.

Essa interação de textos não é, porém, autônoma, como também os significados atribuídos às intervenções, interpretações ou objetos da paisagem não são livre e individualmente construídos. Em artigo de 1988, James e Nancy Duncan (DUNCAN; DUNCAN, 1988, p. 117, 126) reconhecem a importância do intertexto e das metáforas na leitura da paisagem. Para eles, esses conceitos são adequados à sua natureza anônima: à paisagem não se pode atribuir uma autoria, porque é um produto da sociedade que a construiu, uma criação intertextual. Mas, imaginar que exista, na leitura da paisagem, completa liberdade e autonomia de interpretação é, para Duncan e Duncan, adotar uma posição perigosa de relativismo extremado, na qual qualquer intervenção seria válida e justificada.

Uma das características daquilo que é referido como pós-modernidade em arquitetura, ou em paisagismo, é a proliferação de cenários, simulações, lugares programados para atividades programadas, histórias inventadas e outros tipos de derivativos, a pretenderem nos convencer que a realidade virtual é uma possibilidade concreta. A intenção deliberada de fazer passar o falso pelo autêntico alimenta-se da tentativa de forçar os limites interpretativos, para criar uma espécie de significado elástico e descontextualizado. Mas, embora um significado seja instável e plural, ele não é infinito, porque interage sempre com um contexto social que, simultaneamente, sugere e restringe as possibilidades de interpretação (DUNCAN; DUNCAN, 1988, p. 120). O domínio intertextual dos significados dispersos e instáveis deve, necessariamente, ancorar-se em contextos sociais específicos nos quais esses significados serão reunidos para produzir uma paisagem. É preciso ver a paisagem, então, como a entretecedura de um conjunto de narrativas dispersas na sociedade, para descobrir as tramas sociais que the conferem inteligibilidade e para valorizar o papel da memória e do esquecimento nesse processo.

Para Milton Santos (SANTOS, 1996, p. 263, 264) a memória é sistematicamente apagada pelos eventos, pelo novo, que trabalha com a descoberta, em substituição à experiência, para criar saberes: enquanto a memória é coletiva, o esquecimento e a conseqüente redescoberta são individuais e diferenciados, enriquecendo as relações interpessoais e a ação comunicativa. Esquecer, lembrar-se, imaginar, simbolizar, criar, reunir, são processos inerentes ao ato de construir uma narrativa. Reunir objetos pertencentes a várias escalas de apreensão, que tanto revelam significados presentes na vida cotidiana dos lugares quanto se comportam como pontos focais que enfatizam a intenção de aglutinar esses significados criando lugares informados, são processos inerentes ao ato de construir uma paisagem. 
Se a paisagem é, assim, uma narrativa espacial a que se pode atribuir todas essas qualidades, o projeto de paisagismo deve funcionar como uma obra aberta, encorajando a participação e a criatividade da sociedade e utilizando-se da ambigüidade, da desconexão e da multiplicidade como estratégias de desafio à ordem estabelecida. Sua principal função não é a de subjugar, mas a de revelar a ordem inerente à natureza por múltiplas aberturas para histórias e memórias. Um outro vetor de significado, criado pela aliança entre projeto e uso, exige investigar como o projeto é lido e decodificado pela sociedade.

O processo de construção do lugar é um processo de representação de relações sociais, que faz com que o simbólico se transforme, por meio de intervenções formais ou informais, em realidades materiais, em ordem efetiva dos objetos sobre o território. Como as relações sociais locais são, na atualidade, cada vez mais influenciadas por fenômenos econômicos, políticos e culturais de caráter global, sua representação por meio de objetos qualificados é uma representação local diversificada - e não determinada a priori - e obedece aos impulsos da escala global.

Sendo assim, parece que apenas pela apropriação efetiva - que transcende o simples uso - de seu lugar de vida, a sociedade pode qualificar as determinações econômicas ou políticas da escala global, construindo uma paisagem narrativa, com sentido cultural.

\section{ARQUITETURA DA PAISAGEM?}

A transformação da paisagem é a própria história de seu uso, a conferir-lhe identidade e significado. Mas é, também, a história da negação de certos processos sociais e do divórcio, favorecido por eles, entre o homem e seu entorno.

O século 18 assistiu ao início dessa cisão na cultura européia, decorrência do processo de industrialização que se instalou naquele continente. $\bigcirc$ cotidiano de suas cidades respondeu aos efeitos das transformações da produção e do consumo, exibindo, na paisagem, a dominação humana sobre o ambiente natural, em escala e velocidade sem precedentes.

Essas condições foram extremamente favoráveis para o aflorar de uma "sensibilidade paisagística" - de origem marcadamente pictórica - que buscava, na esfera do consumo, a volta à condição pré-industrial, norteada pela idéia de construir paisagens naturais capazes de dissimular as próprias condições de produção e reprodução social as quais thes davam origem. Sob esse devaneio romântico gestaram-se projetos grandiosos de arborização urbana, de implantação de parques e jardins, propostas de cidades utópicas para comunidades auto-suficientes - auto-sustentáveis? - em sintonia virtual com os ritmos naturais e com as virtudes da integração campo-cidade.

O reino humano e o reino natural mantinham-se separados, mas, mimetizavam-se, fundindo-se, ao longo dos séculos 18 e 19, na ornamentação das fachadas dos edifícios, decoradas com motivos vegetais destinados a oferecer-lhes a intencionalidade da natureza. A cisão entre a ordem da razão humana e a irracionalidade dos domínios vegetais era, porém, pré-requisito para a contemplação nostálgica do paraíso perdido. 
"Enquanto a exploração técnica tendia a declarar guerra contra a natureza, jardins e parques tentavam uma reconciliação, um armistício local, introduzindo o sonho da paz possível e, com esse fim, o homem seguia conservando, na imaginação, os entornos naturais intactos." (STAROBINSKI, 1993)

Já nas primeiras décadas do século 20, o clima de instabilidade política, social e econômica que se abateu sobre a Europa constituiu um quadro extremamente desfavorável para a realização de praças públicas, parques ou mesmo jardins particulares, bloqueando os eventuais avanços do paisagismo. Os impulsos decisivos para sua renovação e reformulação partiram, nas Américas, dos arquitetos modernistas, em sua busca de integração entre os espaços edificados e não-edificados. Embora essa disposição permeasse a maioria dos projetos, a relação do paisagismo com a pintura permanecia como um dos principais referenciais dos paisagistas, produzindo espaços públicos escultóricos ou de formas biomórficas e curvas. Os jardins, praças e parques constituíam, na paisagem das cidades, contribuições importantes, porém assinadas e datadas, caracterizando a atividade do paisagismo como uma intencionalidade artística requintada, pautada, geralmente, no equilíbrio entre áreas vegetadas e pavimentadas.

É importante ressaltar, ainda uma vez, que transformações na paisagem são inerentes à atividade humana e o conjunto dessas transformações é obra da coletividade e não de algumas poucas pessoas. A atividade do paisagismo, até os anos 50 do século 20, esteve inscrita em uma "definição ideológica da arquitetura, que distingue, que seleciona entre todos os produtos humanos, alguns produtos especiais, que são privilegiados na consideração, que são criados por pessoas especiais, que são usados por pessoas especiais e que são julgados e discutidos em âmbito específico e especial" (MAGNOLI, 1994, p. 17). Mesmo quando, à visão artística do paisagismo veio somar-se a visão ambiental - cujo precursor foi Garrett Eckbo - enfatizando a paisagem como sistema vivo e alterando a escala de compreensão e de atuação do paisagismo, o quadro de "criação e uso especiais" pouco se alterou e os jardins emblemáticos da modernidade que então se prenunciava continuavam sendo produzidos pelas mesmas pessoas e para as mesmas pessoas, assumindo, agora, a qualificação de arquitetura da paisagem.

Se até os anos 30, os espaços não-edificados eram resolvidos durante sua própria execução - a exemplo, entre outros, do Campo de Santana (RJ), de Glaziou - ou, mais raramente, seguindo planos genéricos previamente desenhados, em uma situação semelhante à da própria arquitetura, aproximadamente a partir daquela década o projeto afirmou-se, também no paisagismo, como metodologia de organização espacial, detaIhando, com desenhos, as propostas de intervenção sobre os espaços não-edificados. É provável que, no caso específico de Burle Marx, o convívio estreito com os arquitetos brasileiros tenha influenciado sua metodologia de trabalho, adaptando o paisagismo à padronização das etapas de projeto difundidas e consolidadas pelos arquitetos. Mas sua fama contribuiu para a difusão da idéia de as atribuições desse profissional serem as de conformar a paisagem, projetando seus espaços não-edificados em perfeita sintonia com os edifícios que eles emolduravam. $\bigcirc$ projeto se tornava inseparável da noção de paisagem, confundindo-se com ela e, mais, com a própria arquitetura. 
Mas, não há como confundir projeto e arquitetura, visto esta trabalhar com um universo de representação voltado para a necessidade de construir, ideologicamente, o projeto de uma sociedade ou de sua escala de valores, marcados no tempo (FERRARA, 1998, p. 28). Isto é, a funcionalidade do objeto - aquilo que ele denota - representada, no ato de projetar, por meio do desenho, será qualificada socialmente, assumindo conotações que revelam os valores da sociedade e sua transformação. Não é possível, também, confundir projeto de paisagismo e paisagem, esta última uma construção social a revelar a acumulação, no tempo, de práticas, técnicas, valores e símbolos culturalmente transmitidos de geração a geração.

O que conferiu modernidade ao paisagismo não foi apenas sua identificação com o projeto arquitetônico como metodologia de representação, mas, principalmente, o caráter público que ele assumiu ao tratar as praças, parques e jardins como espaços coletivos, acessíveis a todos, indiscriminadamente, desenhados e construídos para receber uso coletivo e para integrar, qualificados por esse uso, o universo dos valores sociais.

Insistir na denominação "arquitetura da paisagem" não significa apenas uma tentativa de delimitar - pela tradução do termo landscape architecture - um campo de atuação profissional que se confunde, no mercado de trabalho, com outros tipos de atuação sobre a paisagem, mas trai, acima de tudo, uma concepção elitista do paisagismo, aquela a que se refere Miranda Magnoli: a do produto especial, criado por pessoas especiais e usado por pessoas especiais, tentando eliminar o caráter público dos lugares urbanos, objeto da atividade do paisagismo.

O maior sintoma dessa elitização está na profusão de lugares criados sob medida para uma clientela que pretende, pela implantação de projetos exclusivos, sublinhar as diferenças sociais exatamente no lugar onde elas devem ser minimizadas: o espaço de uso público. Essa arquitetura da paisagem forja identidades meramente simbólicas, exatamente porque trabalha com a ausência de referências sociais objetivas. Tudo é subjetivo, cativo do gosto tido como refinado e culto, nessa paisagem criada para atender apenas aos devaneios da imaginação.

Enquanto a vida se torna cada vez mais privada, pela censura implícita imposta ao uso coletivo daquilo que é público, essa paisagem cenário, produto da confusão entre projeto construído e paisagem, revela a intenção de aglutinar objetos sem conexão e sem raízes culturais, para criar a ilusão de a desagregação social poder ser revertida por um suposto respeito às diferenças, respeito que nos abriria as portas para o mito da "inclusão social".

É o paisagismo, mais uma vez, a serviço da negação, na esfera do consumo, daquilo que se arma na esfera da produção das cidades: a violência, a segregação, a supressão dos direitos à moradia, à saúde, ao trabalho, à educação, a espoliação cotidiana a que estamos todos sujeitos, seriam compensados, na arquitetura da paisagem, por uma espécie de ideologia da diversidade, um suposto respeito à individualidade cultural de pessoas as quais, reduzidas a simples coadjuvantes da realidade urbana, seriam compensadas dessa alienação pelo prazer estético de desfrutar de espaços públicos condizentes com seu padrão de consumo. "A lógica que aí se esconde, não é outra 
senão a da racionalidade sabidamente perversa do mundo da reprodução material da sociedade, para o qual o reforço das particularidades é a contrapartida da globalização." (ARANTES, 1998, p. 187)

À paisagem, historicamente, cabe o papel de mostrar a verdadeira face dos conflitos sociais e, portanto, ao paisagismo não é dada a atribuição de dissimular aquilo que desagrada a algumas parcelas da sociedade, que nada fazem além de impor, por meio de pressões econômicas, padrões urbanísticos incompatíveis com sua real atuação social. A verdadeira arquitetura da paisagem, se é que existe uma, é construída todos os dias pelo conjunto da sociedade, construção que o paisagismo toma parte, propondo alternativas de uso e de qualificação de espaços coletivos, democráticos e acessíveis. Outras formas de interpretar sua atuação não passam de tentativas de restringir a participação de todos na conformação de seu ambiente de vida.

À paisagem, enfim, não se pode atribuir uma autoria, porque ela é um produto da sociedade que a construiu, é uma criação intertextual.

\section{Bibliografia}

ARANTES, Otília. Urbanismo em fim de linha. São Paulo: Edusp, 1998.

ARTIGAS, João Batista Vilanova. A função social do arquiteto. São Paulo: Nobel, 1989.

BURLE MARX, Roberto. Paisagem, botânica e ecologia. In: LEENHARDT, J. Nos jardins de Burle Marx. São Paulo: Perspectiva, 1996.

COSTA, Lucio. Lucio Costa: Registro de uma vivência. São Paulo: Empresa das Artes, 1995.

DUNCAN, James S.; DUNCAN Nancy G. [Re]reading the landscape. Environment and Planning D. Society and space, Londres, n. 6, p. 117-126, 1988.

FERRARA, Lucrécia D'Alessio. Arquitetura e linguagem: investigação contínua. In: OLIVEIRA, A. C.; FECHINE, Y. (Orgs.). Visualidade, urbanidade e intertextualidade: São Paulo: Hacker, 1998.

ECO, Umberto. Travels in hipereality. Londres: Pan Books, 1987.

Function and sign: the semiotics of architecture. In: $\mathrm{LEACH}, \mathrm{Neal}$ (Org.). Rethinking architecture, a reader in cultural theory. Londres: Routledge, 1997.

Kant e l'ornitorinco. Milão: Bompiani, 1997.

LAURIE, Michael. An introduction to landscape architecture. Londres: Pitman, 1978.

LEENHARDT, Jacques. O jardim: jogos de artifícios. In: LEENHARDT, J. Nos jardins de Burle Marx. São Paulo: Perspectiva, 1996.

MAGNOLI, Miranda. Experiência de ensino de paisagismo para arquitetos na FAUUSP. São Paulo: FAUUSP, 1981.

Paisagem - pesquisa sobre o desenho do espaço. Paisagem e ambiente - Ensaios, São Paulo, FAUUSP, n. 1 e 2, p. 9-24, 1994.

MONTEIRO, Carlos Augusto de Figueiredo. A questão ambiental no Brasil: 1960-1980. São Paulo: Igeog-USP, 1981. POTTEIGER, Matthew; PURINTON, Jamie. Landscape narratives. Nova York: John Wiley \& Sons, 1998.

SANTOS, Milton. A natureza do espaço. São Paulo: Hucitec, 1996.

Por uma geografia nova. São Paulo: Hucitec, 1980.

STAROBINSKI, Jean. La invención de la libertad. In: KENNETH, Frampton (Org.). Historia crítica de la arquitectura moderna. Barcelona: Gustavo Gilli, 1993. 